\title{
Erratum to: Thermoelectric Energy Harvesting from Transient Ambient Temperature Gradients
}

\author{
ANDRÉ MOSER, ${ }^{1,3}$ METIN ERD, ${ }^{2}$ MILOS KOSTIC, ${ }^{2}$ KEITH COBRY, ${ }^{1}$ \\ MICHAEL KROENER, ${ }^{1}$ LEONHARD M. REINDL, ${ }^{2}$ and PETER WOIAS ${ }^{1}$ \\ 1.-Laboratory for Design of Microsystems, Department of Microsystems Engineering - IMTEK, \\ University of Freiburg, Georges-Koehler-Allee 102, 79110 Freiburg, Germany. 2.-Laboratory for \\ Electrical Instrumentation, Department of Microsystems Engineering - IMTEK, University \\ of Freiburg, Georges-Koehler-Allee 103, 79110 Freiburg, Germany. 3.-e-mail: andre.moser@ \\ imtek.de
}

Erratum to: Journal of ELECTRONIC MATERIALS,

Vol. 41, No. 6, 2012

DOI 10.1007/s11664-011-1894-4

Leonhard M. Reindl was inadvertently missing from the list of authors of the original paper.

The online version of the original article can be found under doi: 10.1007/s11664-011-1894-4. 